\title{
Consistent changes in the taxonomic structure and functional attributes of bacterial communities during primary succession
}

\author{
Rüdiger Ortiz-Álvarez $\mathbb{B}^{1} \cdot$ Noah Fierer $^{2} \cdot$ Asunción de los Ríos $^{3} \cdot$ Emilio O. Casamayor $^{1} \cdot$ Albert Barberán $^{4}$
}

Received: 18 September 2017 / Revised: 11 January 2018 / Accepted: 13 January 2018 / Published online: 20 February 2018

(c) International Society for Microbial Ecology 2018

\begin{abstract}
Ecologists have long studied primary succession, the changes that occur in biological communities after initial colonization of an environment. Most of this work has focused on succession in plant communities, laying the conceptual foundation for much of what we currently know about community assembly patterns over time. Because of their prevalence and importance in ecosystems, an increasing number of studies have focused on microbial community dynamics during succession. Here, we conducted a meta-analysis of bacterial primary succession patterns across a range of distinct habitats, including the infant gut, plant surfaces, soil chronosequences, and aquatic environments, to determine whether consistent changes in bacterial diversity, community composition, and functional traits are evident over the course of succession. Although these distinct habitats harbor unique bacterial communities, we were able to identify patterns in community assembly that were shared across habitat types. We found an increase in taxonomic and functional diversity with time while the taxonomic composition and functional profiles of communities became less variable (lower beta diversity) in late successional stages. In addition, we found consistent decreases in the rRNA operon copy number and in the high-efficient phosphate assimilation process (Pst system) suggesting that reductions in resource availability during succession select for taxa adapted to low-resource conditions. Together, these results highlight that, like many plant communities, microbial communities also exhibit predictable patterns during primary succession.
\end{abstract}

Electronic supplementary material The online version of this article (https://doi.org/10.1038/s41396-018-0076-2) contains supplementary material, which is available to authorized users.

Rüdiger Ortiz-Álvarez

rudigerortiz@gmail.com

$\triangle$ Albert Barberán

barberan@email.arizona.edu

1 Integrative Freshwater Ecology Group, Centre for Advanced Studies of Blanes (CEAB), Spanish Research Council (CSIC), Blanes, Catalonia 17300, Spain

2 Department of Ecology \& Evolutionary Biology, Cooperative Institute for Research in Environmental Sciences, University of Colorado, Boulder, CO 80309, USA

3 Microbial Ecology and Geomicrobiology Group, Museo Nacional de Ciencias Naturales, Spanish Research Council (CSIC), Madrid 28006, Spain

4 Department of Soil, Water, and Environmental Science, University of Arizona, Tucson, AZ 85721, USA

\section{Introduction}

The study of ecological succession, or the process by which biological communities develop over time, has been integral to the development of ecological theory [1-3]. Primary succession begins with the colonization and mobilization of nutrients by pioneer communities in a recently exposed environment with little to no pre-existing life, such as after glacier retreat or after volcanic eruptions [3]. Despite the important role of microorganisms as early colonizers in primary succession, most of the studies examining community change during primary succession have historically focused on plant communities [4]. However, primary succession can also occur in microbial habitats, including the surfaces of plant leaves and flowers [5-7], exposed rock surfaces [8], glacial sediments [9-11], animal guts [12], and biofilms [13]. Furthermore, studying primary succession from a microbial perspective has the added advantage that ecologists can examine community development patterns in a time frame far shorter than what would be required to track primary succession patterns in plant or animal communities [14]. Spurred, in part, by the widespread use of 
DNA sequencing-based methods to survey microbial communities, there has been a recent increase in the number of studies characterizing the trajectories of microbial communities during primary succession across a wide range of different habitats [14-16]. It remains unclear whether similar trends occur in microbial community structure across the diverse array of habitat types in which primary succession can occur.

Patterns in ecological succession across different studies conducted in distinct habitats can be compared by focusing on the changes in the number and frequency of taxa (i.e., alpha diversity) and on the degree of differentiation/variability among local communities within a given region or habitat (i.e., beta diversity) between early and late successional stages within individual studies. Since successional trajectories may be highly irregular and non-linear, depending on the specific characteristics of each habitat and the timing of environmental and/or community changes [4, 17] we do not expect the timing of successional change to be identical across systems. Nevertheless, we can still contrast those microbial communities found in early vs. late successional stages to broadly compare successional patterns across habitats [2, 3, 18]. In general, the number of different species is expected to increase from early to later stages of succession due to an increase in potential niches, resource diversity, and habitat heterogeneity [3, 19, 20]. For example, the number of plant species doubled 2 years after the 1980 eruption of Mount Saint Helens [21] and, in human infant gut communities, bacterial diversity doubled over the first year of life [12]. In addition to changes in alpha diversity, we would also expect the degree of differentiation (i.e., dissimilarity in overall composition) between communities at a given successional stage to decrease with time due to selection of suitable taxa under homogeneous environmental filters [18]. However, this has not yet been empirically evaluated across habitats.

In addition to changes in the taxonomic composition and diversity of communities during succession, we would also expect the distribution of traits within these communities to change. During succession, the ability of both plants [22] and microbes [23] to establish, survive, and thrive is based, in part, on their functional traits that confer colonization potential, competitive advantage, or stress tolerance. Changes in functional groups or community-averaged traits linked to ecological succession can be predicted with a high degree of confidence, and documenting such changes can give added insight into patterns of community assembly during succession [3, 4, 24]. For example, a study in grasslands showed that communities converged in trait composition at late successional stages, although the same plant communities were taxonomically distinct across latesuccessional plots [25]. Such functional and trait-based approaches have substantially improved the mechanistic understanding of ecological processes affecting ecosystem structure and dynamics [26]. For instance, the colonization sequence of algal surfaces by bacterial communities is not consistent with respect to species composition but there are consistent patterns in the functional attributes of the community members [27]. Despite the potential importance of traits, so far only the rRNA operon copy number (a proxy for maximum growth rate [28]) has been proposed as a genomic trait linked to ecological succession in different ecosystem types [29]. We aim to identify whether there are other microbial traits that shift in a predicable manner during ecological succession across habitats.

We carried out a meta-analysis of 121 16S rRNA gene libraries from 17 different studies to explore how the taxonomic diversity and composition of microbial communities change with succession and whether there are corresponding changes in specific functional attributes (inferred from genomic information) with succession. These data were derived from seven distinct habitats (gut-associated, plant-associated, soil, river biofilm, microbial mats, and saline lakes). Because the temporal dynamics of succession are likely to be distinct across this range of habitats and because the timing of sample collection differed across studies, we focused on comparing communities within each study across "early" vs. "late" stages of succession (with "early" and "late" samples defined separately for each study depending on the data available). Although the selected studies were restricted to those in which succession started with pioneer microorganisms, they differed with respect to the types of communities found in their respective habitats, the environmental conditions, and the pace of succession. We also compared how specific community-weighted microbial traits varied between early and late successional stages, under the assumption that some functional attributes should consistently become more or less important during different stages of succession, regardless of the habitat in question.

\section{Materials and methods}

\section{Sample selection and habitat classification}

We compiled 61 early and 60 late $16 \mathrm{~S}$ rRNA gene libraries from the available literature (Tables S1 and S2). "Early" successional stages were represented by those samples selected shortly after the start of community development, while the "late" successional stages were represented by those samples within each study collected at the last time points available. To focus on primary succession regardless of different successional timespans, for the selection of sites/individuals we required external environmental conditions to be stable, if possible without strong perturbations 
or nutrient input changes. For statistical consistency, samples were selected with at least two replicates for early and late stages, summarized into 27 sites or individuals. Replicates of each sample were those taken from the same individual/site if possible (gut microbiomes), or from an equivalent source based on the conditions described in the original articles when sampling required destruction of the original sample (i.e., phyllospheres). Samples were classified as gut-associated (A), plant-associated (B), soil chronosequence (C), and water-associated (D) microbial communities. Within these categories, we considered different subcategories (habitat types): infant gut (A1-A4), primate gut (A5-A10), plant-associated (B1-B4), soil chronosequence $(\mathrm{C} 1-\mathrm{C} 4)$, salt marsh chronosequence (C5-C8), river biofilm (D1), saline shallow lakes (D2-D4), and Hydra development (D5).

\section{Sequence processing}

Sequences originating from 454 and Illumina technologies were trimmed using Trimmomatic [30], cutting the first and last eight nucleotides, and trimming the rest of the sequence when the average quality of four nucleotides fall below 15 . We kept only sequences with a minimum length of 150 nucleotides. Sequences from Sanger sequencing were left untreated. In order to associate taxonomy to genome content, we used a 16S rRNA database [31] linked to the IMG genomic database [32]. Processed sequences were matched to $16 \mathrm{~S}$ rRNA gene records available in the PATRIC genomic database (as of January 2016) [31] using the usearch_global command [33]. This allowed us to cluster sequences of unequal lengths to a certain percentage of identity, despite being limited to the number of sequenced genomes available. A total of 1,098,744 sequences had a match of at least $97 \%$ with a sequenced genome, up to 1844 genomic matches. This approach allows a compromise between statistical consistency and taxonomic resolution, and has been previously shown successful to detect relationships between spatial distribution and genomic traits in soil bacteria [34]. Genomic matches averaged a total of $48.6 \%$ of the sequences (Fig. S1). In the analysis, only 14 phylotypes belonged to Archaea, so all the results displayed here respond to patterns in Bacteria.

\section{Functional predictions}

Metagenomic successional data sets across different habitats would be the best option for functional evaluation [35], but unfortunately available data sets are still limited. Functional predictions based on representative genomes are, however, still useful for the estimation of genomic and metabolic potential $[29,36]$. For that purpose we downloaded from IMG [32] a functional matrix of 8191 gene categories
(KEGG orthologs), their counts per genome, and genomic traits (rRNA operon copy number, $\mathrm{G}+\mathrm{C}$ content and genome size) for 1844 genomic matches. Prediction required matching of the 16S rRNA gene at the 97\% identity level, although we acknowledge that some strains within this level may have distinct functional signatures [37] or environmental distributions [38]. Therefore, further studies are encouraged to confirm our observations based on functional predictions. We calculated weighted-community trait abundance per replicate, combining the functional data and the relative abundance matrix of genomic matches. We assessed the relative amount of carbon fixation (genes prkB: K00855 and rbcS: K01602), nitrogen fixation (genes anfG: K00531, nifD: K02586, glnA: K01915, and nifK: K02591), and high-efficiency inorganic phosphate transport (genes pstB: K02036, pstC: K02037, and pstA: K02038), averaging the weighted KEGG abundances per process in the different samples between early and late stages of succession.

\section{Diversity calculations}

For alpha diversity, the Shannon index measures the amount of information contained in a system based on the number of species and their frequencies. Since alpha diversity measures are highly sensitive to sequencing depth, and original studies yielded different per-sample sequencing depths, we calculated the Shannon index after averaging the values from 100 rarefactions to 50 sequences per replicate sample. Shannon values estimated by subsampling to 500 and 1000 sequences per sample were well correlated with the Shannon values estimated by randomly selecting only 50 sequences per sample (both, $r>0.99, p<0.001$ ). No rarefaction was conducted for any other analysis, and other transformations were applied to standardize data without losing information [39]. Functional Shannon diversity was calculated on the community-weighted KEGG profiles per sample, weighting by relative abundances. For changes in community similarity (i.e., beta diversity), we calculated the Bray-Curtis dissimilarity metric between early and late communities for both the taxonomic and functional profiles (based on the whole KEGG profiles) after Hellinger transformation of non-rarefied matrices. We explored community dissimilarity differences with "habitat" and "succession stage" as sources of variation (permutational multivariate analysis of variance using distance matrices) regardless of the study of origin (ADONIS). The same analysis was used to search for differences in weighted occurrence values by succession stage in taxa and genes (using Euclidean distances with w-occurrence values as the input matrix). Then we compared only the replicates of the same sample (site or individual). If at least two replicates were available per sample (all except B1 and B3), the difference between 


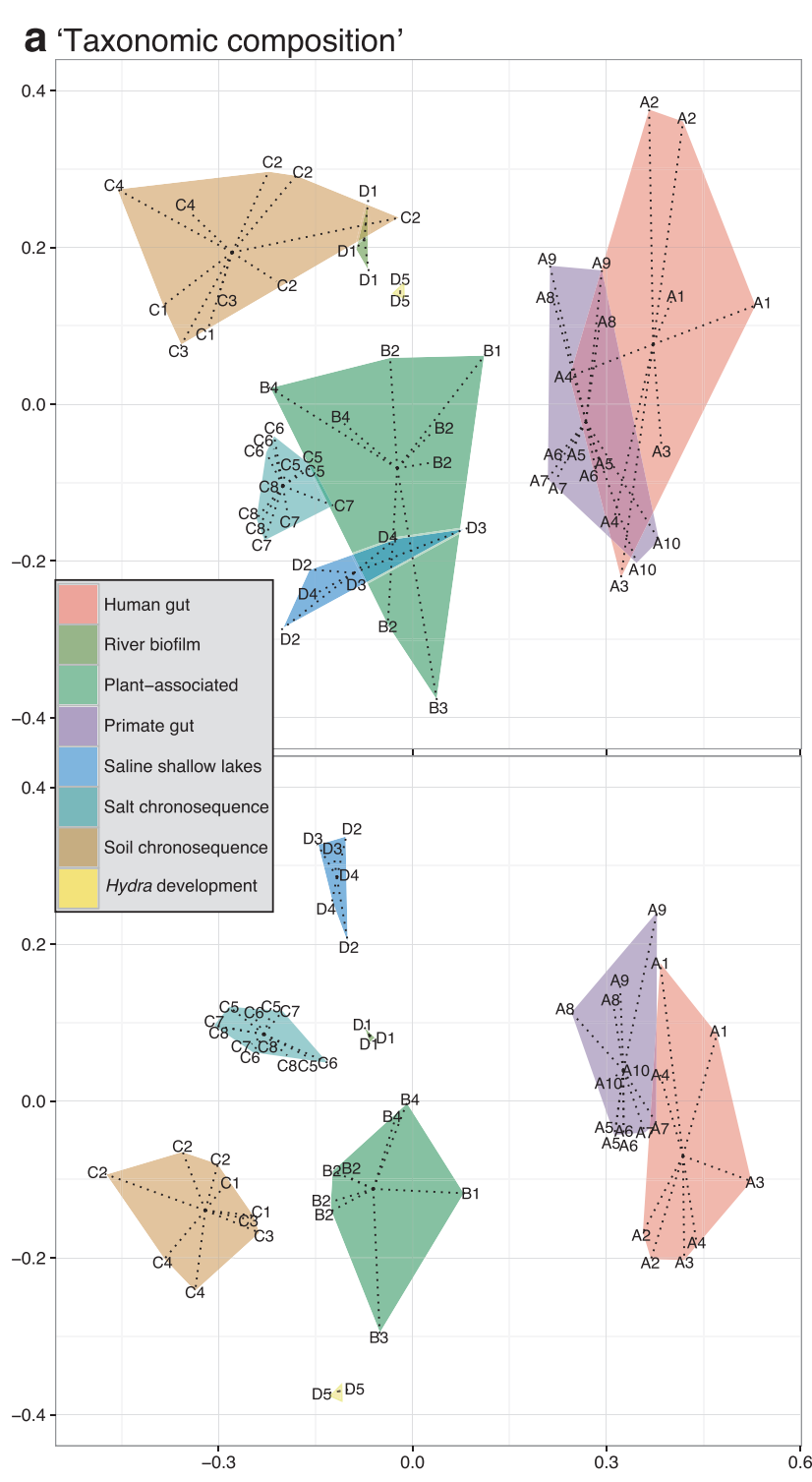

b 'Functional gene composition'

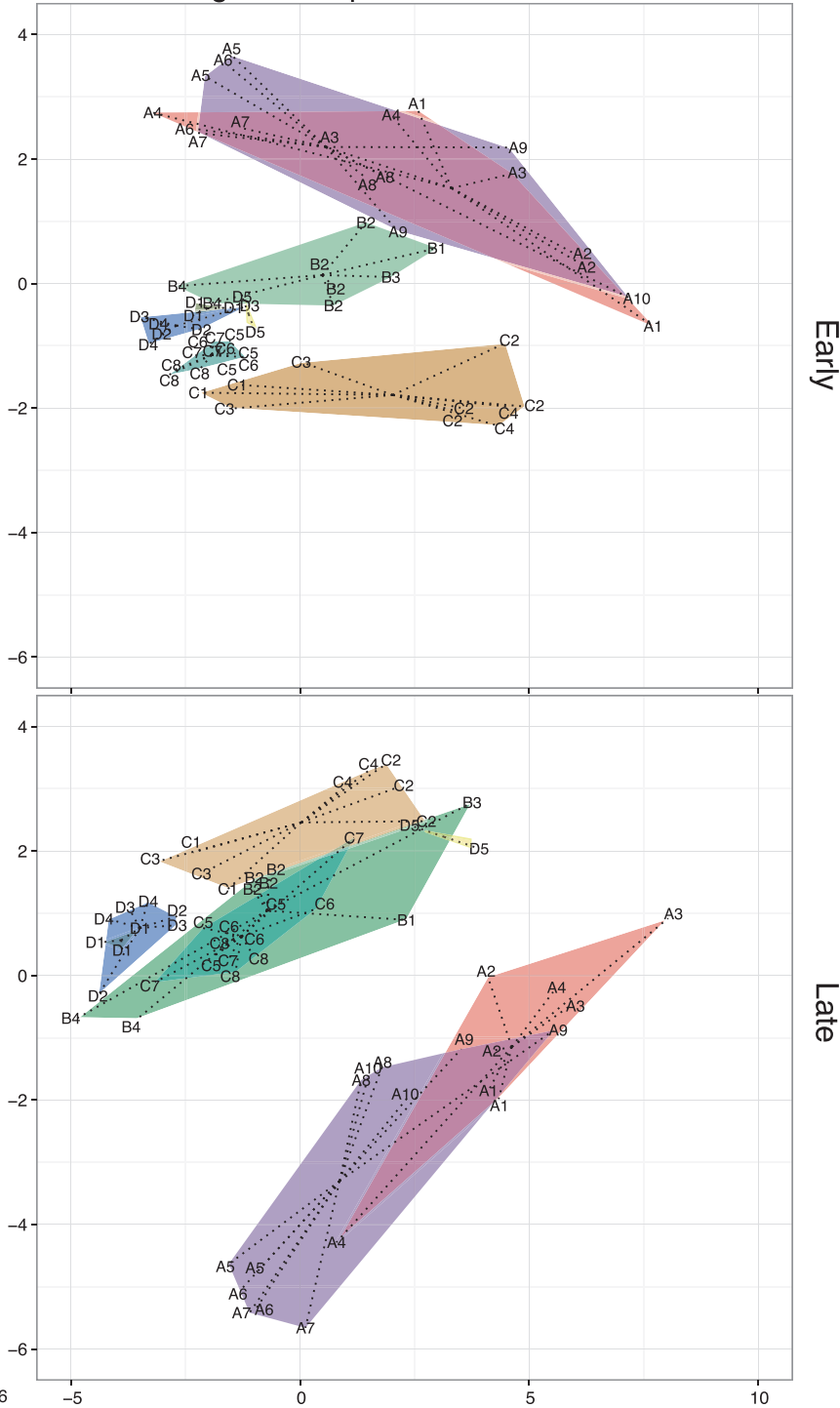

Fig. 1 Comparison of early and late-stage successional samples in non-metric multidimensional scaling ordinations based on Bray-Curtis dissimilarities of taxonomic (a), and functional (b) matrices

"late" and "early" successional stages was calculated. If more than two replicates were available, we used the mean of late distances minus the mean of early distances. A10 samples were removed from early vs. late comparisons because of an extremely high difference of sequences, although they were still included in multivariate ordinations. A simplified version of the $\mathrm{R}$ script is available online (https://github.com/Rudigerceab/succession_ismej).

\section{Results and discussion}

To compare the communities across the 17 studies we started by matching the 16S rRNA gene sequences available for each study to the corresponding genomes available in
IMG database [32]. This step was necessary as the selected studies differed with respect to the molecular methods used to characterize the microbial communities, making direct comparisons across studies difficult. Additionally, having whole-genome information allowed us to determine how the functional attributes of the communities varied over the course of succession. However, we acknowledge that by focusing solely on those bacterial taxa for which wholegenome information is available, we are excluding many taxa for which genomes from closely related taxa are not available. The proportion of sequences that matched the genome database was $49 \%$ across all samples and it ranged from nearly $60 \%$ in the primate gut data set to $8 \%$ in the salt marsh habitat. Interestingly, samples representing early successional stages typically had a higher proportion of 
genome matches per habitat (Fig. S1). Because the ubiquitous, faster-growing bacteria tend to be over-represented in genome databases due to their relative ease of cultivation [40], we would expect a higher number of genome matches where such bacterial types were more abundant. This has ecological significance, since it implies that there are more opportunistic, faster-growing bacteria in early successional stage communities. Additionally, we calculated overall averaged occurrences of the matched genomes per successional stage. An aggregated value of occurrence weighted by relative abundances per sample can indicate if taxa in those samples are, on average, more ubiquitous or more specialized in their habitat preferences. We observed that late successional stage microbial communities had less ubiquitous taxa than early stage communities (mean phylotype weighted-occurrence was 19.65 in early communities compared to 17.01 in late communities). Results were almost significant when considering all samples within an habitat (ADONIS $R^{2}=0.02, p=0.08$ ), and significant when dividing only per sample (ADONIS $R^{2}=0.02, p=$ 0.02 ), highlighting that those taxa that are more abundant in communities during the early stages of succession tend to be more widely distributed in most habitats, except soil chronosequences and plant communities (Fig. S3a).

\section{Habitat drives strong community differentiation in late successional stages}

It has been repeatedly shown that different habitats harbor distinct microbial communities [41, 42]. Not surprisingly, our results confirmed that the different habitats harbored communities that were distinct in taxonomic composition, both in the early and late stages of succession (Fig. 1a; see Fig. S2 for the distribution of major phyla across habitats). On average, only $8 \%$ of phylotypes (range 1.8-19.3\%) in early successional samples and only $6 \%$ of phylotypes $(0.5-15 \%)$ in late successional samples were shared between any pair of habitat types. When partitioning dissimilarities for the sources of variation (habitat and succession stage), we observed that in addition to habitat (ADONIS $R^{2}=0.40, p=0.001$ ), the successional stage was strongly significant and dependent on the habitat, although the percentage of variation explained was smaller (ADONIS $R^{2}=0.08, p=0.001$ ). Indeed, microbial communities were better differentiated with less overlap across habitat types in late successional stages than in early stages (ANOSIM: $R=$ $0.92, p<0.001 ; R=0.73, p<0.001$, respectively). For example, primate gut samples [43] were far more differentiated from human gut samples $[12,44-46]$ in the late stages of succession compared to the communities found in these distinct hosts at the early stages of succession (ANOSIM $R=0.29, p=0.007$ and $R=0.57, p<0.001$, for early and late-stage comparisons, respectively).
We next compared the relative abundances of different gene categories, as calculated from the matched genomes [32] (Fig. 1b), across successional stages. When partitioning dissimilarities for the sources of variation, habitat was a strong predictor of function (ADONIS $R^{2}=0.52, p=$ $0.001)$. The successional stage was again strongly significant and dependent on the habitat, although the percentage of variation explained was small (ADONIS $R^{2}=$ $0.05, p=0.002)$. We further observed that although the differentiation among communities from different habitats with respect to their annotated gene content was weaker than when we simply focused on taxonomic composition, functional changes across habitats were still significant in both late (ANOSIM: $R=0.66, p<0.001$ ) and early successional stage communities (ANOSIM: $R=0.43, p<$ 0.001). In other words, the communities found in different habitats were still distinct with respect to their genomic attributes, but such differentiation was lower than when we simply focused on the taxa present. Given that genomic strategies between gut symbionts and free-living bacteria are fundamentally different [47], it was not surprising to observe a weak differentiation within gut symbiont habitats and free-living habitats (water, soils, and plant phyllospheres; Fig. 1b). Since each gene category is an orthologous group of different genes with analogous functions, such weaker differentiation could be related to functional redundancy. That is, a common functional core of the genomic repertoire is present across communities in different habitats [48], a result that may reflect annotation biases toward "housekeeping" genes and other genes that are widely shared across taxa. As with the taxonomic patterns, late successional stage communities showed on average significantly fewer widely distributed genes than early stage communities (mean functional weightedoccurrence 464.46 in early communities compared to 323.46 in late communities, ADONIS $R^{2}=0.005, p=$ 0.002, Fig. S3b).

We would expect stochastic processes (processes that incorporate random variation such as random dispersal, ecological drift, or historical contingency) to be more important in structuring early stage successional communities [49]. Likewise, deterministic processes (that is, processes that lead to predictable outcomes such as environmental selection, biotic competition, or facilitation) are probably more important in structuring communities in later stages [18]. Taken together, our results show that early succession microbial communities are not just random subsets from a regional pool of species, instead they are the result of habitat-specific environmental filtering in regional pools [50]. However, this environmental filtering effect is stronger in late succession communities, when there is an increase in the habitat specificity of both taxa and annotated genes (Fig. 1). In fact, habitat selection is evident in those 


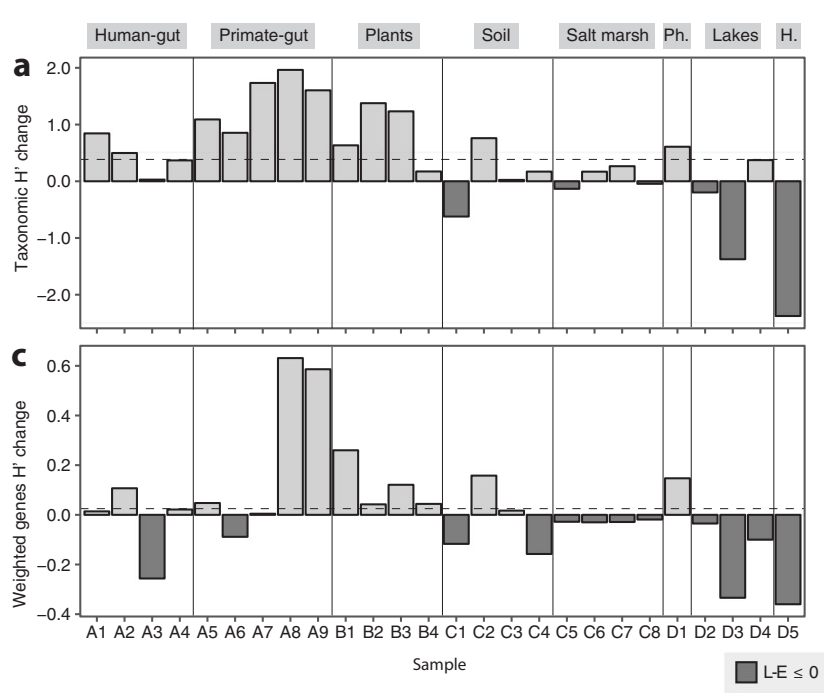

Fig. 2 Changes between late and early stages of diversity metrics. Taxonomic (a) and functional (c) Shannon index $\left(\mathrm{H}^{\prime}\right)$, and beta diversity based on Bray-Curtis dissimilarities of taxonomy (b) and

environments subject to the influence of airborne colonizers (i.e., phyllosphere communities or temporal lakes) and are clear examples of these ecological processes. Airborne colonizers in early communities of plant surfaces are dispersed and later selected to form distinct community compositions [5]. In lakes, aerial colonizers [51] and soil colonizers [52] are environmentally selected by the conditions of each lake to assemble the resulting communities.

\section{Equivalent diversity changes in different habitats along succession}

We compared the taxonomic and functional diversity of the communities in early vs. late successional stages. Taxonomic alpha diversity, measured using the Shannon index $\left(\mathrm{H}^{\prime}\right)$ after standardizing sequencing effort, was generally higher in late stages of succession for most of the studied habitats (Fig. 2a). Although alpha diversity of functional genes followed the same general trend, the patterns were more variable than with taxonomic diversity (Fig. 2c). In general, we would expect that diversity would typically increase from early to late stages of succession due to an increase in potential niches, resource diversity, resource availability, and habitat heterogeneity $[3,20]$. However, an increase in interspecific competition during the later stages of succession might counterbalance this increase in diversity [53]. The successful establishment of highly competitive organisms that become abundant under specific environmental conditions can explain this decline in diversity at late stages. In the microbial data sets analyzed, this decline is clearly observed in the development of Hydra, where the highly competitive bacteria Curvibacter dominates late-stage successional communities [54], and

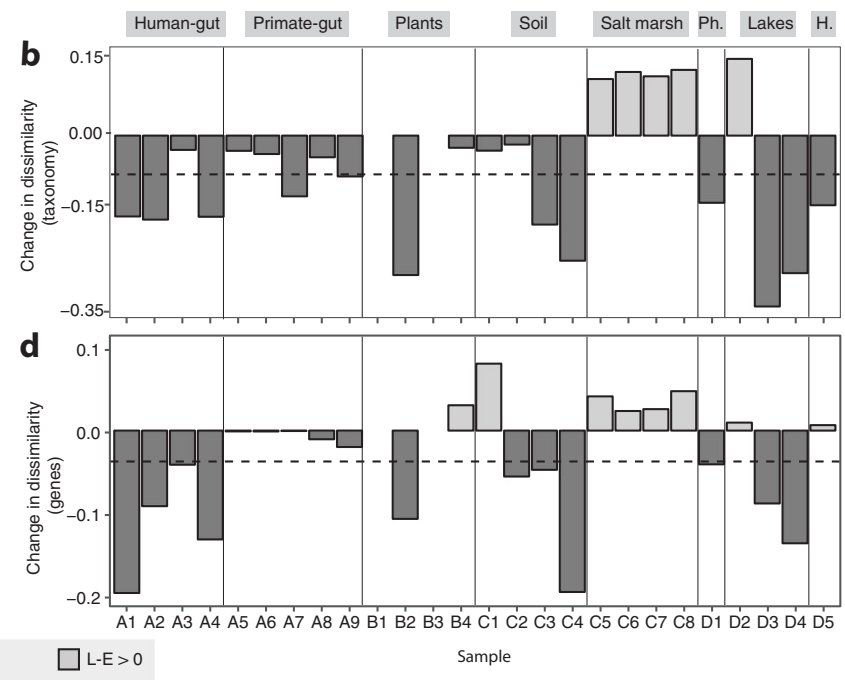

functions (d). A discontinuous line represents the overall mean change. The abbreviations "Ph." and "H." indicate the "Phormidium river biofilm" and "Hydra" samples, respectively

also in the saline shallow lakes where a few salinity tolerant taxa dominate at late successional stages [55].

After assessing the changes in the number and frequency of taxa and functional genes, we explored the degree of community differentiation (beta diversity) between early and late successional stages. Considering all samples within a given habitat, later successional communities were consistently more similar to one another regarding their taxonomic composition than early successional communities (Fig. 1), and this was consistent by sample (Fig. 2b). Functional dissimilarity followed the same trend (Fig. 2d), that is, we found more functional convergence (more similar communities) at later stages of succession. The salt marsh chronosequence communities were the only exception to this general trend. It has been proposed that saline environments tend to develop strong gradients with heterogeneous conditions [55, 56] and anaerobic microsites $[20,57]$ that might enhance historical contingency and priority effects [58]. Interestingly, not a single microbial habitat showed both taxonomic community divergence (dissimilar communities) and functional convergence, a pattern observed in plant communities at later successional stages [25]. In some cases, we might expect that as succession proceeds, communities would tend to establish a more stable state with the surrounding environment $[3,53]$. Ecological theory posits that a single stable state or equilibrium is likely to happen in systems with small regional species pools, high rates of connectivity, and low productivity $[50,58]$, such as primary successional systems. We have shown that different samples from the same habitat with similar conditions develop similar communities over time. This result follows expectations, and is likely explained by the effect of environmental filters on 
Fig. 3 Changes in rRNA operon copy number (a) and highefficient phosphate transport (b) community-weighted functional traits. A discontinuous line represents the overall mean change
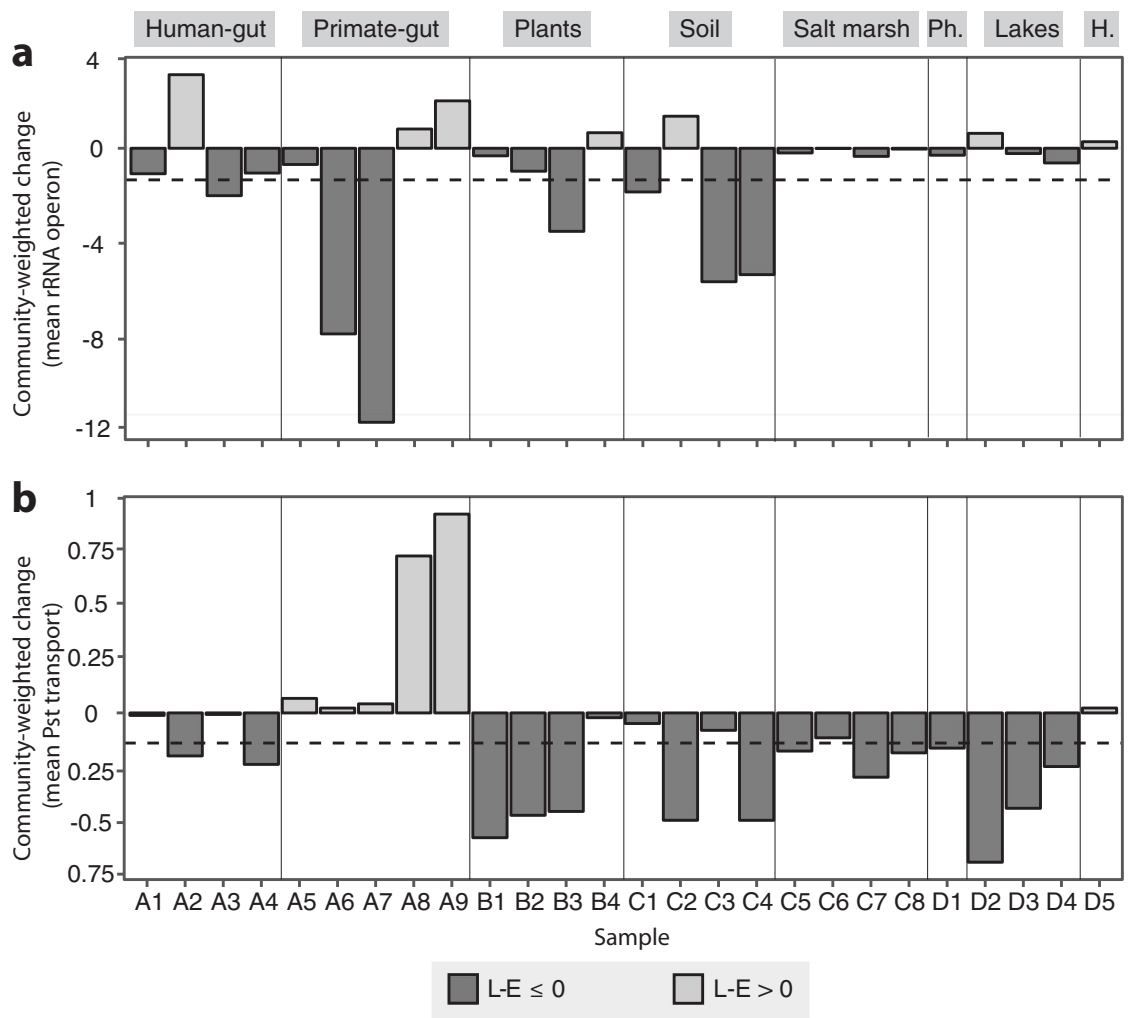

community assembly [59]. We can potentially predict the late-stage composition of microbial communities along succession given enough information on habitat characteristics, but such predictions would be less accurate for early stage communities.

\section{Detection of changes in functional strategies along succession}

We explored how functional traits aggregated per community (community-weighted traits) changed between early and late successional stages. We noticed that trait changes were more variable and complex than patterns in alpha diversity, even within the same habitat. Of the six traits evaluated (Figs. 3, S4), only two of them showed strong consistent signals across habitats. As previously reported $[28,29]$, we observed a general decrease in average rRNA operon copy numbers in most late-stage successional samples (Fig. 3a). Bacteria with higher rRNA operon copy numbers are typically more copiotrophic and have higher maximum growth rates, while microbes with lower rRNA operon copy number are expected to be slower growers and better competitors at later successional stages [28, 29]. Other microbial traits expected to also change consistently with successional stage such as genome size $[34,60,61]$ or $\mathrm{G}+\mathrm{C}$ content [62-64] did not vary consistently in the habitat types included in this meta-analysis (Fig. S4). Further studies on how microbial traits shift across successional stages are needed to make strong predictive inferences on microbial community assembly.

Nutrient availability is known to have a direct impact on succession trajectories $[9,65]$. Although we did not observe any trends for carbon or nitrogen fixation genes (Fig. S4), we found a consistent decrease in genes associated with the uptake and mobilization of inorganic phosphate (Pst gene system) in late-stage successional communities (Fig. 3b). Phosphorus (P) availability can often limit bacterial growth $[66,67]$, and its assimilation is more efficient in bacteria than in other organisms, such as phytoplankton [68, 69]. Traits related to phosphate uptake are expected to be important in many oligotrophic systems where labile forms of organic phosphorus are likely to be less available [7072]. However, changes in phosphate uptake capabilities are an understudied component of microbial community changes during primary succession. Our results indicate that inorganic phosphorus assimilation is a relevant trait in microbial communities during the early stages of primary succession in all the habitats studied, except the Hydra and primate-gut samples, maybe the latter due to the short timespan and a specific type of change in the primates [43]. Also, nitrogen and carbon fixation changes, although heterogeneous, tended to be stronger in the plant and soil communities than in the gut communities (Fig. S4), indicating the differential importance of these processes per type of habitat and growth substrate [19]. The observed changes in both rRNA copy number and the Pst gene 
system suggest that later successional stages have relatively more slow growers (oligotrophic organisms) adapted to lower nutrient availability than early successional stages.

\section{Conclusions and perspectives}

Successional patterns in community composition have been traditionally studied with plant communities [1, 3, 4, 73]. By combining studies that have examined primary succession patterns across a wide variety of habitats, we were able to identify reasonably consistent and predictable trends in community composition, diversity, and functional attributes across successional gradients, trends that are in agreement with current concepts about how plant communities shift during primary succession. The understanding of these changes opens opportunities in a varied scope of research [74]. For example, the change of communities along the development of animal and plant diseases [75, 76] could be predicted based on the diversity changes here observed. Also, further research could focus on communities affected by global change based on the observed importance of $\mathrm{P}$ limitation and biogeochemical cycles [77]. Understanding the ecological processes behind microbial primary succession may be especially useful within restoration and conservation frameworks [78] tracking the progression of community change between early and late stages.

Acknowledgements This work would not have been possible without the original articles that studied ecological succession. We thank all the authors from the original articles; especially we thank S Pérez-Ortega and MA Fernández-Martínez for their valuable feedback and sampling of glacial chronosequences (C4), and Xavier Triadó-Margarit for sampling of D2-D4 in Monegros. ROA was supported through the Spanish FPI $\mathrm{PhD}$ scholarships program (MINECO). Funding was provided by grants BRIDGES, CGL2015-69043-P (ROA and EOC), and CTM2015-64728C2-2-R (AR) from the Spanish Office of Science (MINECO).

\section{Compliance with ethical standards}

Conflict of interest The authors declare that they have no conflict of interest.

\section{References}

1. Cowles HC. The ecological relations of the vegetation on the sand dunes of Lake Michigan. BotGaz. 1899;27:97-117. 167-902, 281-308, 361-91.

2. Margalef R. Diversity, stability and maturity in natural ecosystems. In: Van Dobben WH, Lowe-McConnell RH, editors. Unifying concepts in ecology SE-12. The Netherlands: Springer; 1975. pp. 151-60.

3. Odum EP. The strategy of ecosystem development. Science. 1969;164:262-70.

4. Connell JH, Slatyer RO. Mechanisms of succession in natural communities and their role in community stability and organization. Am Nat. 1977;111:1119-44.
5. Maignien L, Deforce EA, Chafee ME, Eren AM, Simmons SL. Ecological succession and stochastic variation in the assembly of Arabidopsis thaliana phyllosphere communities. MBio. 2014;5. e-pub ahead of print https://doi.org/10.1128/mBio. 00682-13.

6. Redford AJ, Fierer N. Bacterial succession on the leaf surface: a novel system for studying successional dynamics. Microb Ecol. 2009;58:189-98.

7. Shade A, S. McManus P, Handelsman J. Unexpected diversity during community succession in the apple. MBio. 2013;4: e00602-12.

8. Mushegian AA, Peterson CN, Baker CCM, Pringle A. Bacterial diversity across individual lichens. Appl Environ Microbiol. 2011;77:4249-52.

9. Fernández-Martínez MA, Pointing SB, Pérez-Ortega S, ArrónizCrespo M, Green TGA, Rozzi R, et al. Functional ecology of soil microbial communities along a glacier forefield in Tierra del Fuego (Chile). Int Microbiol. 2017;19:161-73.

10. Brown SP, Jumpponen A. Contrasting primary successional trajectories of fungi and bacteria in retreating glacier soils. Mol Ecol. 2013;23:481-97.

11. Wei STS, Fernandez-Martinez MA, Chan Y, Van Nostrand JD, de los Rios-Murillo A, Chiu JMY, et al. Diverse metabolic and stress-tolerance pathways in chasmoendolithic and soil communities of Miers Valley, McMurdo Dry Valleys, Antarctica. Polar Biol. 2015;38:433-43.

12. Koenig JE, Spor A, Scalfone N, Fricker AD, Stombaugh J, Knight R, et al. Succession of microbial consortia in the developing infant gut microbiome. Proc Natl Acad Sci USA. 2011;108:4578-85.

13. Foxman B, Wu J, Farrer EC, Goldberg DE, Younger JG, Xi C. Early development of bacterial community diversity in emergently placed urinary catheters. BMC Res Notes. 2012;5:332.

14. Jessup CM, Kassen R, Forde SE, Kerr B, Buckling A, Rainey PB, et al. Big questions, small worlds: microbial model systems in ecology. Trends Ecol Evol. 2004;19:189-97.

15. Fernández-Martínez MA, Pérez-Ortega S, Pointing SB, Green TGA, Pintado A, Rozzi R et al. Microbial succession dynamics along glacier forefield chronosequences in Tierra del Fuego (Chile). Polar Biol. 2017. e-pub ahead of print https://doi.org/10. 1007/s00300-017-2110-7.

16. Nemergut DR, Schmidt SK, Fukami T, O’Neill SP, Bilinski TM, Stanish LF, et al. Patterns and processes of microbial community assembly. Microbiol Mol Biol Rev. 2013;77:342-56.

17. Kreyling J, Jentsch A, Beierkuhnlein C. Stochastic trajectories of succession initiated by extreme climatic events. Ecol Lett. 2011;14:758-64.

18. Dini-Andreote F, Stegen JC, van Elsas JD, Salles JF. Disentangling mechanisms that mediate the balance between stochastic and deterministic processes in microbial succession. Proc Natl Acad Sci USA. 2015;112:E1326-32.

19. Fierer N, Nemergut D, Knight R, Craine JM. Changes through time: integrating microorganisms into the study of succession. Res Microbiol. 2010;161:635-42.

20. Jackson CR. Changes in community properties during microbial succession. Oikos. 2003;2:444-8.

21. Del Moral R, Bliss LC. Mechanisms of primary succession: insights resulting from the eruption of Mount St Helens. Adv Ecol Res. 1993;24:1-66.

22. Read QD, Moorhead LC, Swenson NG, Bailey JK, Sanders NJ. Convergent effects of elevation on functional leaf traits within and among species. Funct Ecol. 2014;28:37-45.

23. Goberna M, Navarro-Cano JA, Valiente-Banuet A, García C, Verdú M. Abiotic stress tolerance and competition-related traits underlie phylogenetic clustering in soil bacterial communities. Ecol Lett. 2014;17:1191-201. 
24. Garnier E, Cortez J, Billès G, Navas ML, Roumet C, Debussche $\mathrm{M}$, et al. Plant functional markers capture ecosystem properties during secondary succession. Ecology. 2004;85:2630-7.

25. Fukami T, Martijn Bezemer T, Mortimer SR, Putten WH. Species divergence and trait convergence in experimental plant community assembly. Ecol Lett. 2005;8:1283-90.

26. McGill BJ, Enquist BJ, Weiher E, Westoby M. Rebuilding community ecology from functional traits. Trends Ecol Evol. 2006;21:178-85.

27. Burke C, Steinberg P, Rusch DB, Kjelleberg S, Thomas T. Bacterial community assembly based on functional genes rather than species. Proc Natl Acad Sci USA. 2011;108:14288-93.

28. Klappenbach JA, Dunbar JM, Thomas M, Schmidt TM. rRNA operon copy number reflects ecological strategies of bacteria. Appl Envir Microbiol. 2000;66:1328-33.

29. Nemergut DR, Knelman JE, Ferrenberg S, Bilinski T, Melbourne B, Jiang L, et al. Decreases in average bacterial community rRNA operon copy number during succession. ISME J. 2015;10:1147-56.

30. Bolger AM, Lohse M, Usadel B. Trimmomatic: a flexible trimmer for Illumina sequence data. Bioinformatics. 2014;30:2114-20.

31. Wattam AR, Abraham D, Dalay O, Disz TL, Driscoll T, Gabbard JL, et al. PATRIC, the bacterial bioinformatics database and analysis resource. Nucleic Acids Res. 2014;42:581-91.

32. Markowitz VM, Chen I-MA, Palaniappan K, Chu K, Szeto E, Pillay M, et al. IMG 4 version of the integrated microbial genomes comparative analysis system. Nucleic Acids Res. 2014;42: D560-7.

33. Edgar RC. Search and clustering orders of magnitude faster than BLAST. Bioinformatics. 2010;26:2460-1.

34. Barberán A, Ramirez KS, Leff JW, Bradford MA, Wall DH, Fierer N. Why are some microbes more ubiquitous than others? Predicting the habitat breadth of soil bacteria. Ecol Lett. 2014;17:794-802.

35. Zhou J, He Z, Yang Y, Deng Y, Tringe SG, Alvarez-cohen L. High-throughput metagenomic technologies for complex microbial community analysis: open and closed formats. MBio. 2015;6: e02288-14.

36. Langille MGI, Zaneveld J, Caporaso JG, McDonald D, Knights D, Reyes Ja, et al. Predictive functional profiling of microbial communities using 16S rRNA marker gene sequences. Nat Biotechnol. 2013;31:814-21.

37. Zhang Y, Lin K. A phylogenomic analysis of Escherichia coli/ Shigella group: implications of genomic features associated with pathogenicity and ecological adaptation. BMC Evol Biol. 2012;12:174.

38. Ortiz-Álvarez R, de los Ríos A, Fernández-Mendoza F, TorralbaBurrial A, Pérez-Ortega S. Ecological specialization of two photobiont-specific maritime cyanolichen species of the genus Lichina. PLoS ONE. 2015;10:e0132718.

39. McMurdie PJ, Holmes S. Waste not, want not: why rarefying microbiome data is inadmissible. PLoS Comput Biol. 2014;10: e1003531.

40. Hugenholtz P, Goebel B, Pace N. Impact of culture-independent studies on the emerging phylogenetic view of bacterial diversity. $\mathrm{J}$ Bacteriol. 1998;180:4765-74.

41. Auguet J-C, Barberan A, Casamayor EO. Global ecological patterns in uncultured Archaea. ISME J. 2010;4:182-90.

42. Lozupone $\mathrm{Ca}$, Knight R. Global patterns in bacterial diversity. Proc Natl Acad Sci USA. 2007;104:11436-40.

43. McKenney Ea, Rodrigo A, Yoder AD. Patterns of gut bacterial colonization in three primate species. PLoS ONE. 2015;10: $\mathrm{e} 0124618$

44. Costello E, Carlisle E, Bik E, Morowitz MJ, Relman DA. Microbiome assembly across multiple body sites in lowbirthweight infants. MBio. 2013;4:e00782-13.
45. La Rosa PS, Warner BB, Zhou Y, Weinstock GM, Sodergren E, HallMoore CM, et al. Patterned progression of bacterial populations in the premature infant gut. Proc Natl Acad Sci USA. 2014;111:12522-7.

46. Vallès Y, Artacho A, Pascual-García A, Ferrús ML, Gosalbes MJ, Abellán JJ, et al. Microbial succession in the gut: directional trends of taxonomic and functional change in a birth cohort of Spanish infants. PLoS Genet. 2014;10:e1004406.

47. Moran NA, Wernegreen JJ. Lifestyle evolution in symbiotic bacteria: insights from genomics. Trends Ecol Evol. 2000;15:321-6.

48. Allison SD, Martiny JBH. Colloquium paper: resistance, resilience, and redundancy in microbial communities. Proc Natl Acad Sci USA. 2008;105:11512-9.

49. Burns AR, Stephens WZ, Stagaman K, Wong S, Rawls JF, Guillemin K, et al. Contribution of neutral processes to the assembly of gut microbial communities in the zebrafish over host development. ISME J. 2016;10:655-64.

50. Chase JM. Community assembly: when should history matter? Oecologia. 2003;136:489-98.

51. Peter H, Hörtnagl P, Reche I, Sommaruga R. Bacterial diversity and composition during rain events with and without Saharan dust influence reaching a high mountain lake in the Alps. Environ Microbiol Rep. 2014;6:618-24.

52. Ruiz-González C, Niño-García JP, del Giorgio PA. Terrestrial origin of bacterial communities in complex boreal freshwater networks. Ecol Lett. 2015;18:1198-206.

53. Margalef R. On certain unifying principles in ecology. Am Nat. 1963;97:357.

54. Franzenburg S, Fraune S, Altrock PM, Künzel S, Baines JF, Traulsen A, et al. Bacterial colonization of Hydra hatchlings follows a robust temporal pattern. ISME J. 2013;7:781-90.

55. Casamayor EO, Triadó-Margarit X, Castañeda C. Microbial biodiversity in saline shallow lakes of the Monegros Desert, Spain. FEMS Microbiol Ecol. 2013;85:503-18.

56. Casamayor EO, Massana R, Benlloch S, Øvreås L, Díez B, Goddard VJ, et al. Changes in archaeal, bacterial and eukaryal assemblages along a salinity gradient by comparison of genetic fingerprinting methods in a multipond solar saltern. Environ Microbiol. 2002;4:338-48.

57. Jackson CR, Churchill PF, Roden EE. Successional changes in bacterial assemblage structure during epilithic biofilm development. Ecology. 2001;82:555-66.

58. Fukami T. Historical contingency in community assembly: integrating niches, species pools, and priority effects. Annu Rev Ecol Evol Syst. 2015;46:1-23.

59. Vellend M. Conceptual synthesis in community ecology. Q Rev Biol. 2010;85:183-206.

60. Konstantinidis KT, Tiedje JM. Trends between gene content and genome size in prokaryotic species with larger genomes. Proc Natl Acad Sci USA. 2004;101:3160-5.

61. Leff JW, Jones SE, Prober SM, Barberán A, Borer ET, Firn JL, et al. Consistent responses of soil microbial communities to elevated nutrient inputs in grasslands across the globe. Proc Natl Acad Sci USA. 2015;112:10967-72.

62. Foerstner KU, von Mering C, Hooper SD, Bork P. Environments shape the nucleotide composition of genomes. EMBO Rep. 2005;6:1208-13.

63. Barberán A, Fernández-Guerra A, Bohannan BJM, Casamayor EO. Exploration of community traits as ecological markers in microbial metagenomes. Mol Ecol. 2012;21:1909-17.

64. Garcia JaL, Fernández-Guerra A, Casamayor EO. A close relationship between primary nucleotides sequence structure and the composition of functional genes in the genome of prokaryotes. Mol Phylogenet Evol. 2011;61:650-8.

65. Knelman JE, Schmidt SK, Lynch RC, Darcy JL, Castle SC, Cleveland CC, et al. Nutrient addition dramatically accelerates microbial community succession. PLoS ONE. 2014;9:e102609. 
66. Correll DL. Phosphorus: a rate limiting nutrient in surface waters. Poult Sci. 1999;78:674-82.

67. Schmidt SK, Cleveland CC, Nemergut DR, Reed SC, King AJ, Sowell P. Estimating phosphorus availability for microbial growth in an emerging landscape. Geoderma. 2011;163:135-40.

68. Brasell Ka, Heath MW, Ryan KG, Wood Sa. Successional change in microbial communities of benthic Phormidium-dominated biofilms. Microb Ecol. 2015;69:254-66.

69. Thingstad TF, Skjoldal EF, Bohne RA. Phosphorus cycling and algal-bacterial competition in Sandsfjord, western Norway. Mar Ecol Prog Ser. 1993;99:239-59.

70. Richardson AE, Simpson RJ. Soil microorganisms mediating phosphorus availability update on microbial phosphorus. Plant Physiol. 2011;156:989-96.

71. Vila-Costa M, Sharma S, Moran MA, Casamayor EO. Diel gene expression profiles of a phosphorus limited mountain lake using metatranscriptomics. Environ Microbiol. 2013;15:1190-203.

72. Zubkov MV, Mary I, Woodward EMS, Warwick PE, Fuchs BM, Scanlan DJ, et al. Microbial control of phosphate in the nutrientdepleted North Atlantic subtropical gyre. Environ Microbiol. 2007;9:2079-89.
73. Clements FE. Plant succession: an analysis of the development of vegetation. Washington, DC: Carnegie Institution of Washington; 1916.

74. Prach K, Walker LR. Four opportunities for studies of ecological succession. Trends Ecol Evol. 2011;26:119-23.

75. Garbeva P, van Veen Ja, van Elsas JD. Microbial diversity in soil: selection microbial populations by plant and soil type and implications for disease suppressiveness. Annu Rev Phytopathol. 2004;42:243-70

76. Buffie CG, Pamer EG. Microbiota-mediated colonization resistance against intestinal pathogens. Nat Rev Immunol. 2013;13:790-801.

77. Rockström J, Steffen W, Noone K, Persson Å, Chapin FS, Lambin E et al. Planetary boundaries: exploring the safe operating space for humanity. Ecol Soc. 2009;14. e-pub ahead of print https://doi. org/10.1038/461472a.

78. Plassart P, Akpa Vinceslas M, Gangneux C, Mercier A, Barray S, Laval K. Molecular and functional responses of soil microbial communities under grassland restoration. Agric Ecosyst Environ. 2008;127:286-93. 